\title{
Conservação pós-colheita do milho verde minimamente processado sob atmosfera controlada e refrigeração ${ }^{1}$
}

\author{
Alexandra Mara Goulart Nunes Mamede ${ }^{2}$, Marcos José de Oliveira Fonseca*3, Antonio Gomes Soares ${ }^{4}$, \\ Israel Alexandre Pereira Filho ${ }^{5}$, Ronoel Luiz de Oliveira Godoy ${ }^{6}$
}

http://dx.doi.org/10.1590/0034-737X201562020004

\section{RESUMO}

O consumo de espigas de milho verde com endosperma normal é tradicional, no Brasil, e a sua comercialização in natura é cada vez maior no mercado de produtos minimamente processados, mostrando a necessidade de mais estudos a respeito de sua vida útil. O objetivo deste trabalho foi avaliar a influência de duas atmosferas controladas $\left(2 \% \mathrm{O}_{2}+8 \% \mathrm{CO}_{2}, 4 \% \mathrm{O}_{2}+8 \% \mathrm{CO}_{2}\right)$ e atmosfera ambiente, na qualidade de milho verde, do tipo normal Embrapa $\mathrm{HT} 1$, minimamente processado, durante 12 dias de armazenamento, a $5{ }^{\circ} \mathrm{C}$. As atmosferas controladas foram eficientes em reduzir a perda de massa das espigas de milho, apresentando também menores valores de acidez titulável, o que indica menor atividade respiratória. Os sólidos solúveis, os carotenoides totais, a zeaxantina, a firmeza e os teores de glicose, frutose e sacarose foram influenciados somente pelo tempo de armazenamento, com maiores teores de açúcares redutores em relação aos da sacarose durante todo o armazenamento. $\mathrm{O}$ valor $\mathrm{L}^{*}$ apresentou decréscimo até o oitavo dia de armazenamento, em todas as atmosferas estudadas, com pequeno aumento no controle até $\mathrm{o} 12^{\circ}$ dia. Todas as amostras analisadas, independentemente das atmosferas de conservação, encontravamse dentro dos limites microbiológicos aceitáveis e seguros para consumo.

Palavras-chave: Zea mays, processamento mínimo, qualidade, pós-colheita.

\section{ABSTRACT}

\section{Post-harvest conservation of fresh cut green corn under control atmosphere and refrigeration}

The consumption of corn on the cob of normal type is traditional in Brazil. Its commercialization, as fresh product, properly cleaned and packaged, is being offered increasingly in the market as fresh cut corn. Therefore, it is necessary more studies about this kind of products. The aim of this study was evaluated the influence of two different atmospheres $\left(2 \% \mathrm{O}_{2}+8 \% \mathrm{CO}_{2}, 4 \% \mathrm{O}_{2}+8 \% \mathrm{CO}_{2}\right.$ atmosphere and room atmosphere) under $5{ }^{\circ} \mathrm{C}$ on the quality of fresh cut corn (Embrapa HT1) on the cob of normal type for 12 days' storage. The control atmospheres were effective in reducing the weight loss of cobs, which also showed lower values of total titratable acidity, which indicates lower respiratory activity. The soluble solids, total carotenoids, zeaxanthin, firmness and the glucose, fructose and sucrose contents were influenced only by the storage time. It can be verified that concentrations of reducing sugars were higher than the sucrose during the storage. The $\mathrm{L}^{*}$ value decreased until 8 days of storage in all the atmospheres studied, with a small increase in control until day 12. All the samples of fresh cut corn studied, independent of the treatment, were within the acceptable microbiologic limits.

Key words: corn on the cob, Zea mays, fresh-cut, control atmosphere, quality, post-harvest.

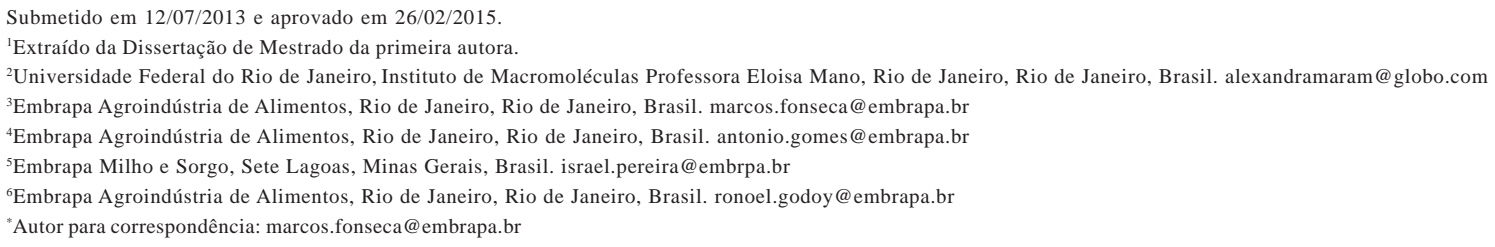




\section{INTRODUÇÃO}

O consumo do milho verde com endosperma normal é tradicional, no Brasil (Pereira Filho \& Cruz, 2003), e o produto in natura é cada vez mais ofertado no mercado de produtos minimamente processados. Porém, por causa do seu alto teor de água ( de 70 a $80 \%$ de umidade), o milho verde é extremamente perecível. Além disso, os cuidados necessários para a manutenção de características adequadas e de higiene, que proporcionariam a comercialização de um produto de alta qualidade, não vêm sendo observados (Marcos et al., 1999; Pereira Filho \& Cruz, 2003).

O uso de refrigeração no armazenamento de produtos hortícolas é um dos mais importantes e simples procedimentos para retardar a deterioração pós-colheita (Nunes \& Emond, 2003), pois o frio é a ferramenta mais efetiva para estender a vida útil de frutas e hortaliças minimamente processadas. Temperaturas baixas contribuem para reduzir a atividade microbiana e as alterações químicas e enzimáticas do vegetal, proporcionando manutenção de qualidade do produto e maior segurança para o consumidor (Brackett, 1987; Brecht et al., 2003).

O uso da atmosfera controlada e modificada deve ser considerado como suplemento da temperatura de refrigeração apropriada e do controle de umidade relativa, tanto no armazenamento como durante o transporte de diversos produtos hortícolas (Kader, 2002; Zagory \& Kader, 1988). De acordo com Kader (2002), as percentagens mínimas de $\mathrm{O}_{2}$ e máxima de $\mathrm{CO}_{2}$ em que o milho doce pode ser armazenado são de 2,0 e 15\%, respectivamente. Cantwell (2002) recomenda o uso de atmosferas contendo de 2 a $4 \%$ de $\mathrm{O}_{2}$ e de 5 a $10 \%$ de $\mathrm{CO}_{2}$.

Para o milho verde enlatado ou cozido na espiga, a umidade, a textura, o aroma e o sabor dos grãos são os principais fatores que levam à aceitação pelo consumidor (Paes et al., 2004). Além disso, a cor do milho verde, conferida pelos carotenoides, é um importante atributo que influencia na aparência e na qualidade nutricional, pelo caráter bioativo desses pigmentos (Vilas Boas, 2002). Entre os carotenoides predominantes no híbrido de milho verde estudado, os principais responsáveis pelas características funcionais para os seres humanos são o $\beta$-caroteno e a $\beta$ criptoxantina, que são precursores da vitamina $A$, e a luteína e a zeaxantina, que são os carotenoides relacionados com a proteção contra a degeneração macular e a catarata (Niizu, 2003).

Este trabalho teve como objetivo avaliar a qualidade de milho verde do tipo normal minimamente processado sob influência da atmosfera controlada e refrigeração, durante 12 dias de armazenamento.

\section{MATERIAL E MÉTODOS}

Como matéria-prima, foram utilizadas espigas de milho verde, do tipo normal, de híbrido pertencente ao programa de melhoramento da Embrapa Milho e Sorgo (Embrapa HT1). O milho foi cultivado em campo experimental da Embrapa Milho e Sorgo, em Sete Lagoas, MG. As espigas foram colhidas no ponto em que os grãos apresentavam-se na fase leitosa, conhecido como "ponto de milho verde", em outubro de 2006, acondicionadas em sacos de estopa, resfriadas em câmara fria, por uma noite, e enviadas de avião, no dia seguinte, para o Rio de Janeiro, sendo transportadas em veículo refrigerado do aeroporto até a Planta Piloto de Fisiologia Pós-Colheita da Embrapa Agroindústria de Alimentos, para realização do processamento mínimo.

O processamento mínimo das espigas foi realizado, utilizando-se as condições higiênicas necessárias, de acordo com a sequência: 1- Recepção da matéria- prima na área externa à sala de processamento mínimo; 2Retirada da palha superficial mais externa, que vem com sujidades do campo, lavagem rápida com água corrente, sobre mesa de inox com dreno; 3 - imersão em tanque com solução aquosa com cloro a $200 \mathrm{mg} \mathrm{L}^{-1}$, à temperatura de $5{ }^{\circ} \mathrm{C}$, por 15 minutos, na área limpa; 4- Drenagem sobre a mesa de inox; 5- Retirada da palha remanescente e dos estigmas; 6- corte da extremidades para uniformização do comprimento da espiga; 7- acondicionamento em bandejas de poliestireno expandido (23,5 x 18,2 cm); e 8- Armazenamento sob refrigeração e atmosferas controladas.

A utilização de bandejas de poliestireno expandido abertas foi para verificação da influência direta das diferentes concentrações gasosas das atmosferas controladas nas espigas de milho, para assim poder usá-las, futuramente, em embalagens modificadas ativas.

Depois do processamento mínimo, as bandejas com o milho verde minimamente processado foram armazenadas, por 12 dias, sob atmosfera controlada e refrigerada, em câmaras de refrigeração a $5 \pm 0,5^{\circ} \mathrm{C}$, com umidade relativa (UR) de $90 \pm 5 \%$ (Mamede et al. 2009). Foram utilizadas as seguintes composições atmosféricas: $\mathrm{AC} 1=2 \% \mathrm{O}_{2}+8 \% \mathrm{CO}_{2}$ (balanço de $\mathrm{N}_{2}$ igual a $90 \%$ ), $\mathrm{AC} 2=4 \% \mathrm{O}_{2}+8 \% \mathrm{CO}_{2}$ (balanço de $\mathrm{N}_{2}$ igual a $88 \%$ ) e controle $=$ atmosfera ambiente. $\mathrm{O}$ controle da atmosfera foi feito em microcâmaras de atmosfera controlada, hermeticamente fechadas e localizadas dentro das câmaras de refrigeração, monitoradas por analisador de gases Kronenberger System Technik, acoplado a sistema computadorizado de controle de atmosfera, para monitoramento e correção dos gases de cada microcâmara, utilizando-se injeção de $\mathrm{N}_{2}$ e $\mathrm{CO}_{2}$, de modo a se obterem as concentrações desejadas. 
As espigas de milho foram avaliadas nos dias $0,3,6$, 9 e 12, quanto às características descritas a seguir:

1. Perda de massa, calculada pela diferença entre a massa inicial das bandejas de milho verde e aquela obtida em cada data de avaliação.

2. Sólidos solúveis (SS), determinados na polpa de milho, por leitura em refratômetro digital Atago PR-101. Os resultados foram expressos em ${ }^{\circ} \mathrm{Brix}$, de acordo com a ISO 2173 (2003).

3. Acidez titulável (AT), determinada por meio do titulador automático Metrohm 794 Basic Titrino, segundo a ISO 750 (1998). A AT foi expressa em g de ácido málico $100 \mathrm{~g}^{-1}$ de polpa.

4. Teores de glicose, frutose e sacarose, determinados segundo Macrae (1998), por cromatografia líquida de alta eficiência (CLAE), com padronização externa, utilizando-se as seguintes condições cromatográficas: injetor manual Rheodyne com loop de $20 \mu \mathrm{L}$, bomba Shimadzu Modelo LC-10AD, detector de índice de refração Waters 2410, coluna Amino 4,6 mm x $250 \mathrm{~mm}$ (Waters - High Performance Carbohydrate), temperatura da coluna $30{ }^{\circ} \mathrm{C}$, fase móvel acetonitrila $75 \%$ em água Milli-Q, com fluxo de 1,3 $\mathrm{mL} \mathrm{min}^{-1}$. Os resultados foram expressos em $\mathrm{g} 100 \mathrm{~g}^{-1}$.

5. Carotenoides: A extração dos carotenoides foi realizada com acetona gelada e, em seguida, o extrato foi submetido à partição para éter petróleo, segundo metodologia adaptada de Rodriguez-Amaya \& Kimura (2004).

5.1. Carotenoides Totais, determinados em espectrofotômetro de UV-Visível Specord 205, com cubeta de quartzo de caminho ótico de $1 \mathrm{~cm}$, no comprimento de onda de $449 \mathrm{~nm}$ ( $\lambda$ máx zeaxantina). Os resultados foram expressos em $\mu \mathrm{g}$ zeaxantina $100 \mathrm{~g}^{-1} \mathrm{de}$ milho doce fresco.

5.2. Quantificação e identificação dos carotenoides, realizadas por CLAE, após a concentração de 3 $\mathrm{mL}$ do extrato etéreo, por meio da evaporação sob fluxo de nitrogênio e diluição em $1 \mathrm{~mL}$ de acetona grau HPLC. A quantificação dos carotenoides foi realizada por padronização externa, utilizando-se os padrões luteína, zeaxantina, $\beta$-criptoxantina e $\beta$-caroteno. As condições cromatográficas utilizadas foram: coluna C30 (3 $\mu \mathrm{m}, 4.6$ mm x 250 mm - YMC Carotenoid Waters), fase móvel com gradiente de metanol/metil t-butil éter, de 80:20 para 15:85 em 36 minutos, fluxo de $0,8 \mathrm{~mL} / \mathrm{min}$, detector photodio de array detector (DAD) 300 a $550 \mathrm{~nm}$ e temperatura da coluna de $30^{\circ} \mathrm{C}$.

Aos $0,2,7,9$ e 11 dias foram realizadas as seguintes avaliações instrumentais:
6. Determinação instrumental da cor $\left(\mathrm{L}^{*} \mathrm{e} \mathrm{b}^{*}\right)$, realizada por reflectância no S \& M Colour Computer modelo SM-4-CH da Suga, no sistema Hunter com abertura de $13 \mathrm{~mm}$ de diâmetro em relação à placa branca. As leituras foram feitas em pontos próximos às duas extremidades e na região central da espiga, num total de duas espigas por repetição.

7. Firmeza dos grãos, determinada por compressão em $10 \mathrm{~g}$ dos grãos de milho verde inteiro e sem cozimento, seguindo metodologia de Paes et al. (2004), adaptada por Mamede et al. (2006), em texturômetro modelo TA-Hdi, da Stable Micro System, acoplado com sonda Kramer Shear Cell HDP/K35, usando célula carga de $5 \mathrm{~kg}$. O equipamento foi previamente configurado com velocidade do pré-teste, de $2,00 \mathrm{~mm} \mathrm{~s}^{-1}$; velocidade de compressão de $2,00 \mathrm{~mm} \mathrm{~s}^{-1}$ e velocidade de retorno de $10 \mathrm{~mm} \mathrm{~s}^{-1}$. Os resultados foram expressos em Newtons (N).

8. Análises Microbiológicas: As amostras de milho verde minimamente processados foram avaliadas, microbiologicamente, nos dias 0,7 e 9 de armazenamento, quanto à presença de coliformes a 35 e a $45^{\circ} \mathrm{C}$, utilizando-se a técnica do número mais provável (NMP) (Swanson et al., 2001); contagem total de fungos filamentosos e leveduras pelo método de plaqueamento em superfície em meio ágar dichloranrose bengal-chloranphenicol (DRBC) (Beuchat \& Cousin, 2001) e contagem total de micro-organismos aeróbios psicrotróficos pelo método de plaqueamento em superfície em meio ágar para contagem padrão (PCA) (Cousin et al., 2001; Morton, 2001). A análise de presença de Salmonella sp. (Andrews et al., 2001) foi realizada somente no sétimo dia de armazenamento.

\section{Delineamento experimental}

1. Para as análises físicas, químicas e físico-químicas, o delineamento adotado foi o inteiramente casualizado, com 15 tratamentos provenientes de um fatorial $3 \times 5$, sendo 3 atmosferas e 5 tempos de armazenamento, com 3 repetições. As análises estatísticas foram realizadas com o programa estatístico Sisvar (Ferreira, 2000). Após a análise de variância, as médias do fator qualitativo (atmosfera controlada), quando significativas, foram comparadas, utilizando-se teste $\mathrm{F}$ e, ou, Tukey, a 5\% de probabilidade. Para o fator quantitativo (tempo de armazenamento), os modelos de regressões polinomiais foram selecionados com base na significância do teste de $\mathrm{F}$ de cada modelo testado, a 1 e $5 \%$ de probabilidade e pelo coeficiente de determinação.

2. Para as análises microbiológicas, os resultados foram interpretados por análise de variância, tendo-se 
nove tratamentos provenientes de um fatorial $3 \times 3$, sendo 3 atmosferas e 3 tempos de armazenamento (1, 7, 9), com 3 repetições.

\section{RESULTADOS E DISCUSSÃO}

Observou-se o aumento da perda de massa do milho verde minimamente processado ao longo do armazenamento, em todas as atmosferas, tendo o controle apresentado valores de perda de massa significativamente maiores que o das atmosferas controladas AC1 e AC2 (Figura 1).

Segundo Chitarra \& Chitarra (2005), perdas da ordem de 3 a $6 \%$ são suficientes para causar declínio acentuado da qualidade de frutas e hortaliças. Considerandose que as perdas de massa mínimas citadas por Chitarra \& Chitarra (2005) sejam suficientes para o declínio da qualidade das espigas de milho verde, pode-se observar, na Figura 1, que os híbridos de milho verde Embrapa HT1, armazenados em atmosfera ambiente poderiam ser comercializados até, aproximadamente, o quinto dia de armazenamento. Nas demais atmosferas, as perdas foram menores que $3 \%$ durante todo o período de armazenamento. Barbosa et al (2012) encontraram perdas de massa entre 3,19 e 3,41\%, para três cultivares de milho doce minimamente processado, armazenado sob atmosfera modificada passiva por nove dias, valores superiores aos encontrados neste estudo para as espigas armazenadas em atmosfera controlada.
A redução da concentração de $\mathrm{O}_{2}$ e, ou, o aumento da concentração de $\mathrm{CO}_{2}$ ao redor de frutas e hortaliças, intactas ou minimamente processadas, podem reduzir sua taxa respiratória (Lana \& Finger, 2000; Soliva-Fortuny \& Martín-Belloso, 2003) e consequentemente, diminuir a perda de massa, o que está de acordo com os resultados encontrados neste estudo e em outros, como, por exemplo, em trabalho realizado por Deák et al. (1987), em que o uso de atmosfera modificada no armazenamento de milho doce diminuiu a perda de água.

No tratamento controle e na AC2 $\left(4 \% \mathrm{O}_{2}+8 \% \mathrm{CO}_{2}\right)$, ocorreu aumento da acidez dos grãos de milho verde minimamente processados, ao longo do armazenamento.

Observando-se a Figura 2, pode-se verificar que a atmosfera ambiente (controle) proporcionou maiores valores de acidez titulável, com aumento de 0,106 para 0,249 mg de ácido málico $100 \mathrm{~g}^{-1}$ de produto fresco, do dia 0 para o $12^{\circ}$ dia de armazenamento, respectivamente. Os maiores valores de acidez titulável, encontrados para o milho verde submetido à atmosfera ambiente, podem indicar maior atividade respiratória, por maior concentração de $\mathrm{O}_{2}$ e menor concentração de $\mathrm{CO}_{2}$, durante o período de armazenamento, pois sabe-se que os ácidos orgânicos são sintetizados a partir de açúcares ou por meio de oxidações, descarboxilações ou carboxilações de outros ácidos, na via respiratória do ciclo de Krebs (Chitarra \& Chitarra, 2005). O aumento da acidez titulável durante o armazenamento de milho verde é, também, relatado por outros autores, como

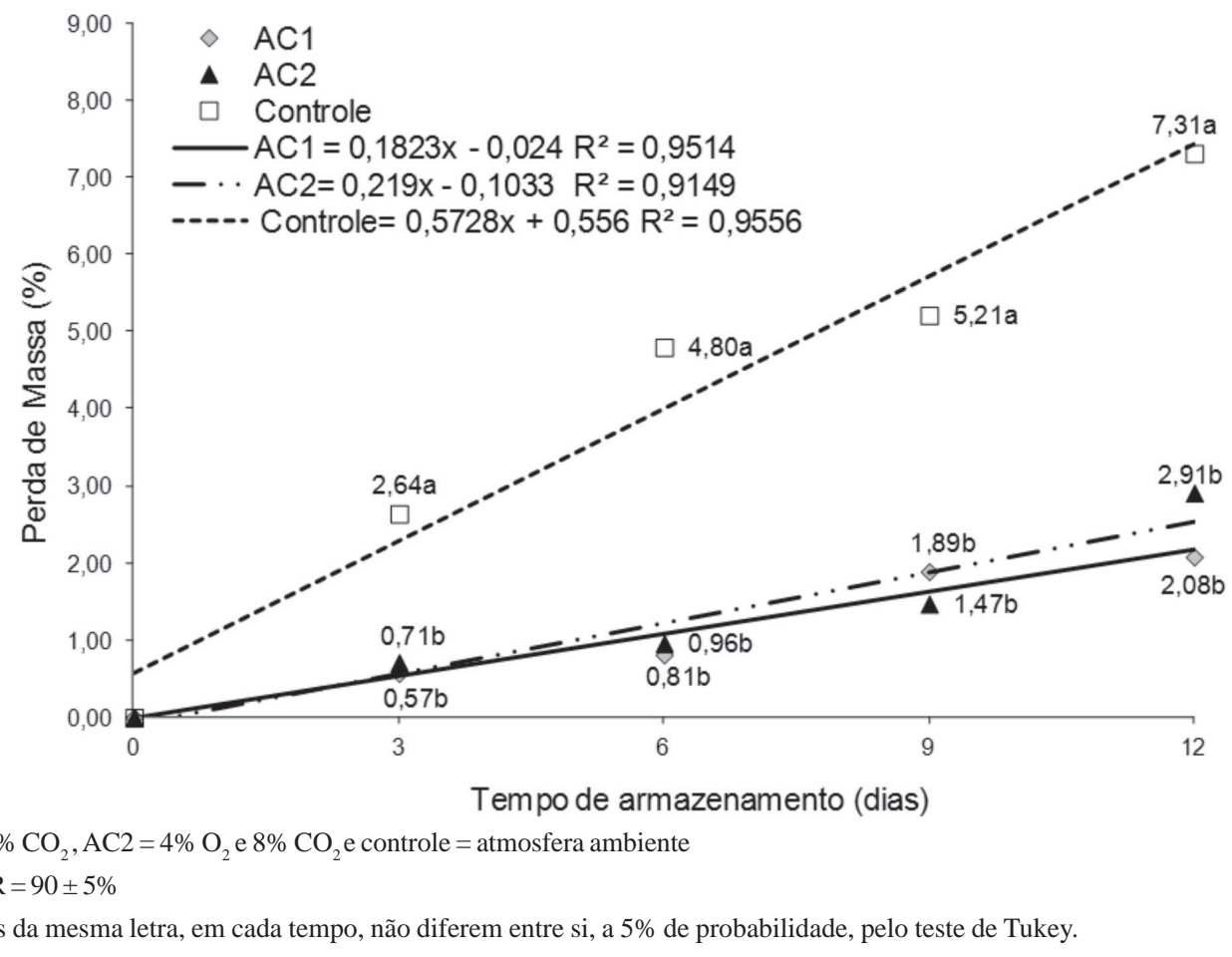

Figura 1 - Perda percentual de massa de milho verde minimamente processado, armazenado sob atmosfera controlada, por 12 dias.

Rev. Ceres, Viçosa, v. 62, n.2, p. 149-158, mar-abr, 2015 
Camacho et al. (2001), em cultivares de milho verde tipo doce armazenados a $4{ }^{\circ} \mathrm{C}$, durante 28 dias.

Os teores de sólidos solúveis (SS) dos grãos de milho verde minimamente processados, independentemente do tratamento, mantiveram-se praticamente constantes durante os três primeiros dias de armazenamento (de 12,2 para $12,3^{\circ}$ Brix), diminuindo, em seguida, até o nono dia (11,4, aos seis dias, e $10,3^{\circ}$ Brix, aos nove dias). Aos 12 dias, a elevação para $11^{\circ}$ Brix pode ser atribuída à perda de água, visualmente detectável pelo murchamento dos grãos na espiga.

Os teores de glicose, frutose e sacarose dos grãos de milho verde minimamente processados não foram afetados pelas atmosferas controladas. Durante todo o período de armazenamento, os teores de glicose dos grãos de milho verde foram superiores, seguidos pelos de frutose e de sacarose (Figura 3). Os teores de glicose e de frutose apresentaram comportamento semelhante ao longo do armazenamento, com aumento até o terceiro dia, seguido por um decréscimo até o nono dia e, novamente, aumento até o final do armazenamento ( $\left.12^{\circ} \mathrm{dia}\right)$. A sacarose apresentou comportamento inverso aos da glicose e da frutose, sendo que, no terceiro e no $12^{\circ}$ dia de armazenamento a sacarose não foi detectada (Figura 3). Pode-se supor que a elevação, inversamente proporcional, dos teores de glicose e de frutose, em relação aos teores de sacarose, pode ser relacionada com a atividade da invertase. Diferentemente do milho doce, para o qual a sacarose é o principal açúcar (Zhu et al., 1992), no milho comum os açúcares redutores apresentam maiores concentrações nos estádios iniciais de maturação
(Tsai et al., 1970; Creech, 1968), que é o caso do milho verde. Isto pode ocorrer por causa da acentuada conversão da sacarose em amido no milho comum.

Os carotenoides identificados no milho comum Embrapa HT1 minimamente processado foram violaxantina, luteína, zeaxantina, $\beta$-criptoxantina e $\beta$-caroteno (Figura 4).

Os carotenoides são responsáveis pela coloração amarela do milho (Scott \& Eldridge, 2005) e, de acordo com Rodriguez-Amaya \& Kimura (2004), a luteína e a zeaxantina são os principais carotenoides encontrados no milho, com menores quantidades de $\beta$-caroteno e $\beta$-criptoxantina, o que está de acordo com os resultados encontrados neste trabalho. Os teores de luteína, $\beta$ caroteno e $\beta$-criptoxantina não diferiram significativamente em função da atmosfera utilizada ao longo do armazenamento ( $\mathrm{p}>0,05)$, apresentando valores médios de: $169,79 \pm 43,6 \mu \mathrm{g} 100 \mathrm{~g}^{-1}, 46,02 \pm 14,8 \mu \mathrm{g} 100 \mathrm{~g}^{-1} \mathrm{e}$ $29,64 \pm 8,9 \mu \mathrm{g} 100 \mathrm{~g}^{-1}$, respectivamente. Barbosa (2013) relatou teores médios de luteína para o cultivar comercial BRS 1030 inferiores ao encontrados neste estudo. No entanto, este cultivar apresentou teores superiores de $\beta$-caroteno e $\beta$-criptoxantina, com valores de $103 \mu \mathrm{g}$ $100 \mathrm{~g}^{-1}, 71 \mu \mathrm{g} 100 \mathrm{~g}^{-1}$ e $136 \mu \mathrm{g} 100 \mathrm{~g}^{-1}$, respectivamente.

Os teores de carotenoides totais (CT) e de zeaxantina não foram afetados pelas atmosferas controladas $(\mathrm{p}>$ $0,05)$, mas somente pelo tempo de armazenamento ( $\mathrm{p}<$ $0,05)$. A zeaxantina foi o carotenoide predominante no milho verde 'Embrapa HT1' minimamente processado. Não foi observada variação significativa para o teor de zeaxantina até o nono dia de armazenamento, com média

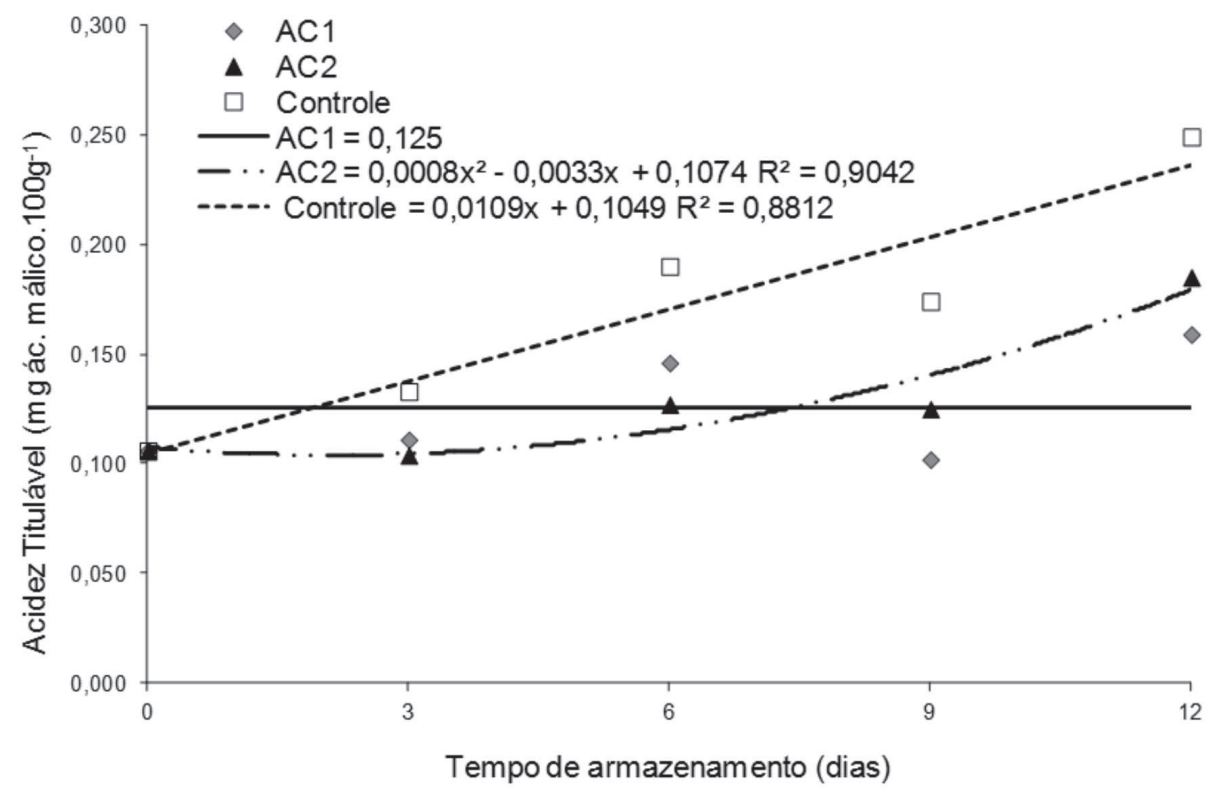

$\mathrm{AC} 1=2 \% \mathrm{O}_{2}$ e $8 \% \mathrm{CO}_{2}, \mathrm{AC} 2=4 \% \mathrm{O}_{2}$ e $8 \% \mathrm{CO}_{2}$ e controle $=$ atmosfera ambiente

$\mathrm{T}=5 \pm 0,5^{\circ} \mathrm{C}, \mathrm{UR}=90 \pm 5 \%$

Figura 2 - Acidez titulável de milho verde minimamente processado, armazenado sob atmosfera controlada, por 12 dias. 
de $366,6 \pm 99,4 \mu \mathrm{g} 100 \mathrm{~g}^{-1}$ de produto fresco, mas observou-se no $12^{\circ}$ dia de armazenamento decréscimo de $29 \%$, com média de 261,4 $\pm 63,9 \mu \mathrm{g}$ de zeaxantina $100 \mathrm{~g}^{-1} \mathrm{de}$ produto fresco.

Os teores de CT encontrados no milho verde minimamente processado diminuíram ao longo do armazenamento. Como a atmosfera controlada não influenciou significativamente nos CT, o decréscimo médio, do dia zero para o $12^{\circ}$ dia de armazenamento, foi de 959,3 \pm 34 , para $752,3 \pm 122,6 \mu \mathrm{g} 100 \mathrm{~g}^{-1}$ de produto, respectivamente.

Azevedo-Meleiro \& Rodriguez-Amaya (2005a; 2005b) relataram decréscimo dos teores de carotenoides em endívia, espinafre e couve minimamente processados e armazenados, durante cinco dias, sob temperatura de $7-9{ }^{\circ} \mathrm{C}$.
Esse decréscimo dos teores dos carotenoides ao longo do armazenamento ocorre, provavelmente, por causa da oxidação dos carotenoides, que é sua principal causa de degradação (Rodriguez-Amaya, 2001). A oxidação dos carotenoides, que pode ocorrer durante o processamento e a estocagem, resulta em perda da cor e de sua atividade biológica, com formação de compostos voláteis que podem conferir aromas e sabores desejáveis ou indesejáveis aos alimentos (Rodriguez-Amaya, 2001).

A firmeza dos grãos do milho verde minimamente processado foi influenciada tanto pela atmosfera controlada $(\mathrm{p}=0,012)$ como pelo tempo de armazenamento $(\mathrm{p}=0,011)$, não sendo influenciada pela interação. A atmosfera ambiente (controle) proporcionou maior firmeza em relação às atmosferas controladas AC1 e AC2, com valores de $332,14 \pm 48 \mathrm{~N} ; 274,41 \pm 76 \mathrm{~N}$ e 278,89

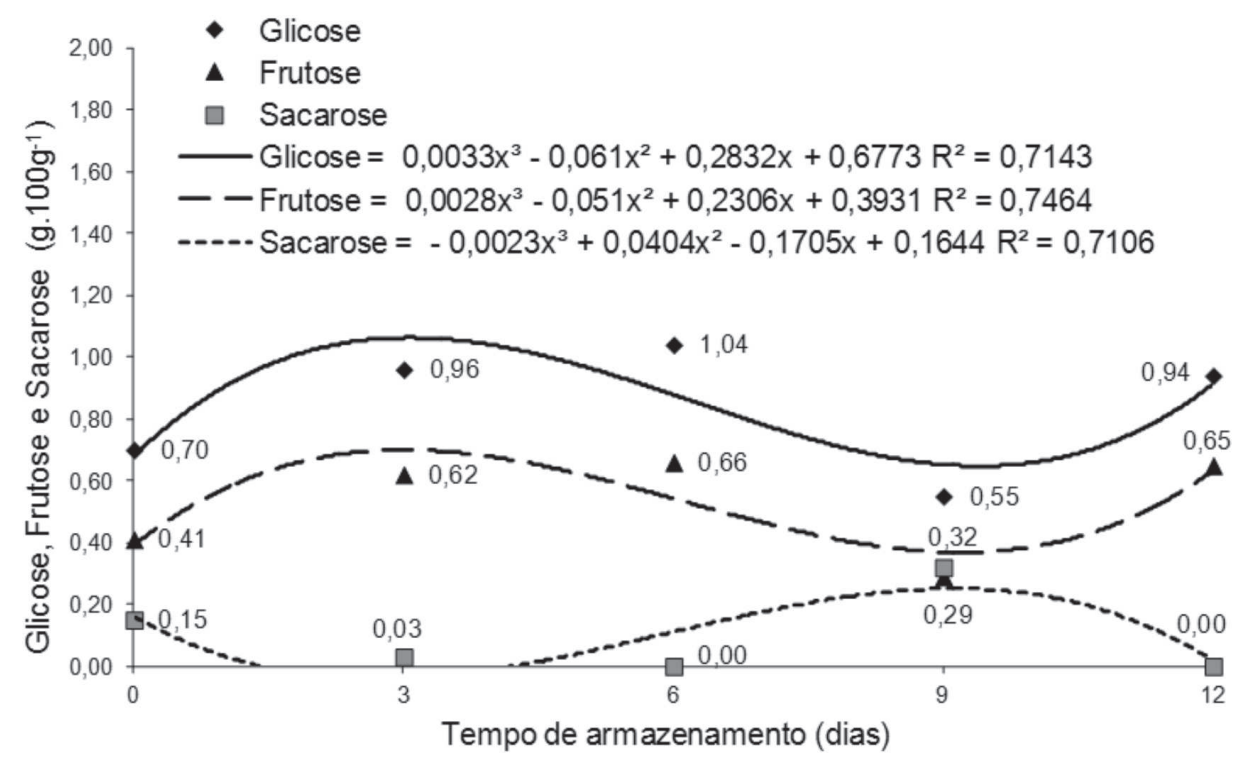

Figura 3 - Teores de glicose, frutose e sacarose de milho verde minimamente processado, armazenado sob atmosfera controlada, por 12 dias.

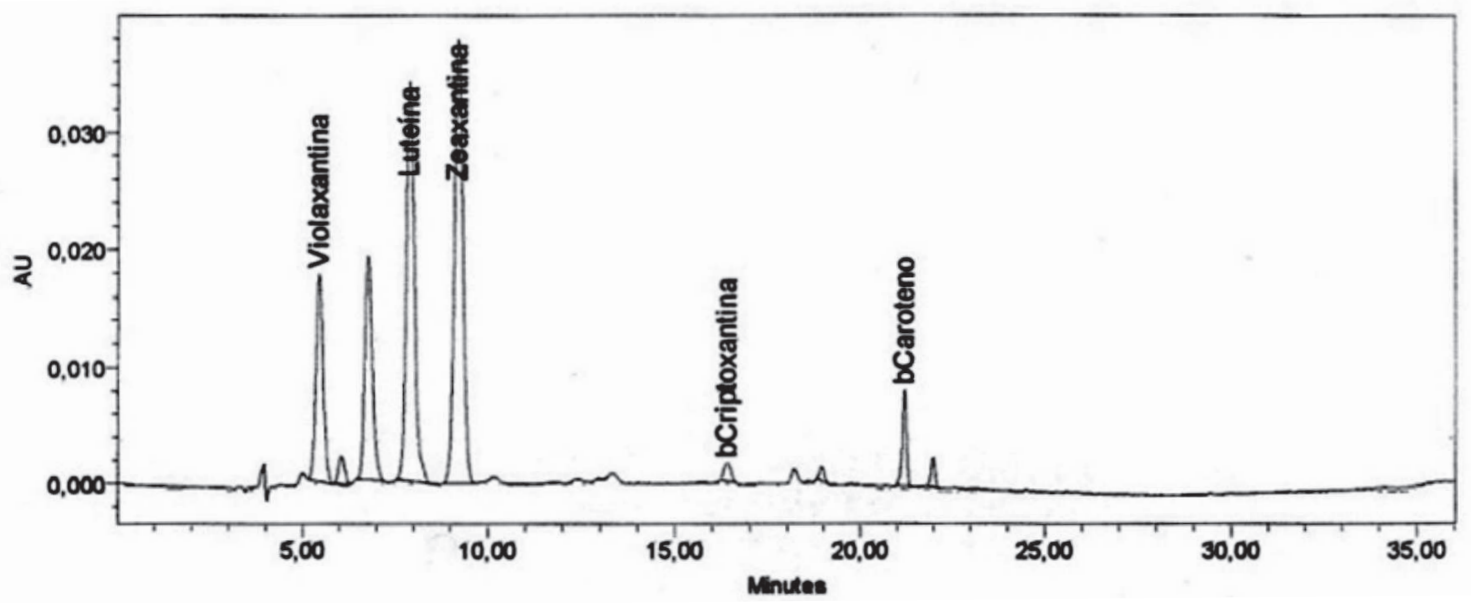

Figura 4 - Perfil Cromatográfico (CLAE-DAD) de carotenoides em milho verde minimamente processado, armazenado sob atmosfera controlada, por 12 dias, $\lambda=450 \mathrm{~nm}$.

Rev. Ceres, Viçosa, v. 62, n.2, p. 149-158, mar-abr, 2015 
$\pm 63 \mathrm{~N}$, respectivamente. O maior valor de firmeza no controle deve-se, provavelmente, à maior perda de água que ocorreu nos produtos armazenados na atmosfera ambiente. Segundo Chitarra \& Chitarra (2005), o teor de umidade tem relação direta com a textura do produto, pois é um dos fatores responsáveis pelo turgor e pela firmeza do tecido.

Em relação ao tempo de armazenamento, avaliandose as médias de ambas as atmosferas controladas, ocorreu decréscimo dos valores de firmeza nos primeiros dias de armazenamento, aproximadamente até o quinto dia (de 350,44 N para 275,84 N). Esta redução inicial pode ter ocorrido por perda de água dos grãos ao longo do armazenamento, diminuindo, assim, o turgor celular, conforme pode ser observado pelo aumento da perda de massa (Figura 1). No sétimo dia de armazenamento, o valor de firmeza aumentou para 313,81 N. Este aumento pode ter ocorrido pela maior resistência ao rompimento das células, em decorrência de um "emborrachamento" que, provavelmente, ocorre nas células do grão de milho, que causa dificuldade no rompimento do tegumento pela sonda do texturômetro. Em seguida, aos nove e 12 dias, a firmeza voltou a diminuir para $278,01 \mathrm{~N}$ e 262,15 $\mathrm{N}$, respectivamente, talvez por causa do processo de senescência e da desorganização da parede celular.

Na Figura 5, pode-se observar que o valor $\mathrm{L}^{*}$ das amostras de milho verde apresentou comportamento semelhante para as atmosferas controladas AC1 e AC2, com decréscimo ao longo do armazenamento. Deák et al. (1987) também encontraram decréscimo dos valores de
$\mathrm{L}^{*}$ para milho doce armazenado a $10{ }^{\circ} \mathrm{C}$ e a $20{ }^{\circ} \mathrm{C}$, durante 16 dias. Como o valor $\mathrm{L}^{*}$ é um indicador do escurecimento, variando de 0 (totalmente preto) a 100 (totalmente branco), o resultado encontrado indica que houve escurecimento da epiderme dos grãos de milho durante o armazenamento. Este escurecimento, não visível a olho nu, pode ter ocorrido pela ação das enzimas polifenoloxidases e peroxidase, que estão associadas a modificações da coloração de produtos hortícolas (Chitarra, 2000). Somente no $11^{\circ}$ dia de armazenamento, ocorreu diferença significativa para o valor $\mathrm{L}^{*}$ entre as atmosferas estudadas. A atmosfera ambiente proporcionou maior valor $\mathrm{L}^{*}$ que as demais (Tabela 1). Esse aumento do valor $\mathrm{L}^{*}$, observado na atmosfera ambiente (Figura 5) nos últimos dias de armazenamento, pode estar relacionado com a maior perda de massa ocorrida nessa condição de armazenamento. Com o ressecamento, os grãos de milho ficam espaçados, então o feixe de luz, que faz a medida de cor instrumental, intercepta o sabugo do milho que possui coloração mais clara que o grão de milho.

$\mathrm{O}$ valor $\mathrm{b}^{*}$ indica variação de coloração, do azul ao amarelo, variando entre $-100 \mathrm{a}+70$. Conforme pode ser observado na Tabela 1, somente no dia 11, houve diferença significativa entre os valores de $b^{*}$ para o milho minimamente processado,e as atmosferas controladas $\mathrm{AC} 1 \mathrm{e}$ AC2 proporcionaram maiores valores de $b^{*}$, com 30,35 e 30,36, respectivamente. Observando-se os valores absolutos dos carotenoides totais citados anteriormente e o valor $b^{*}$, pode-se verificar relação direta entre eles.

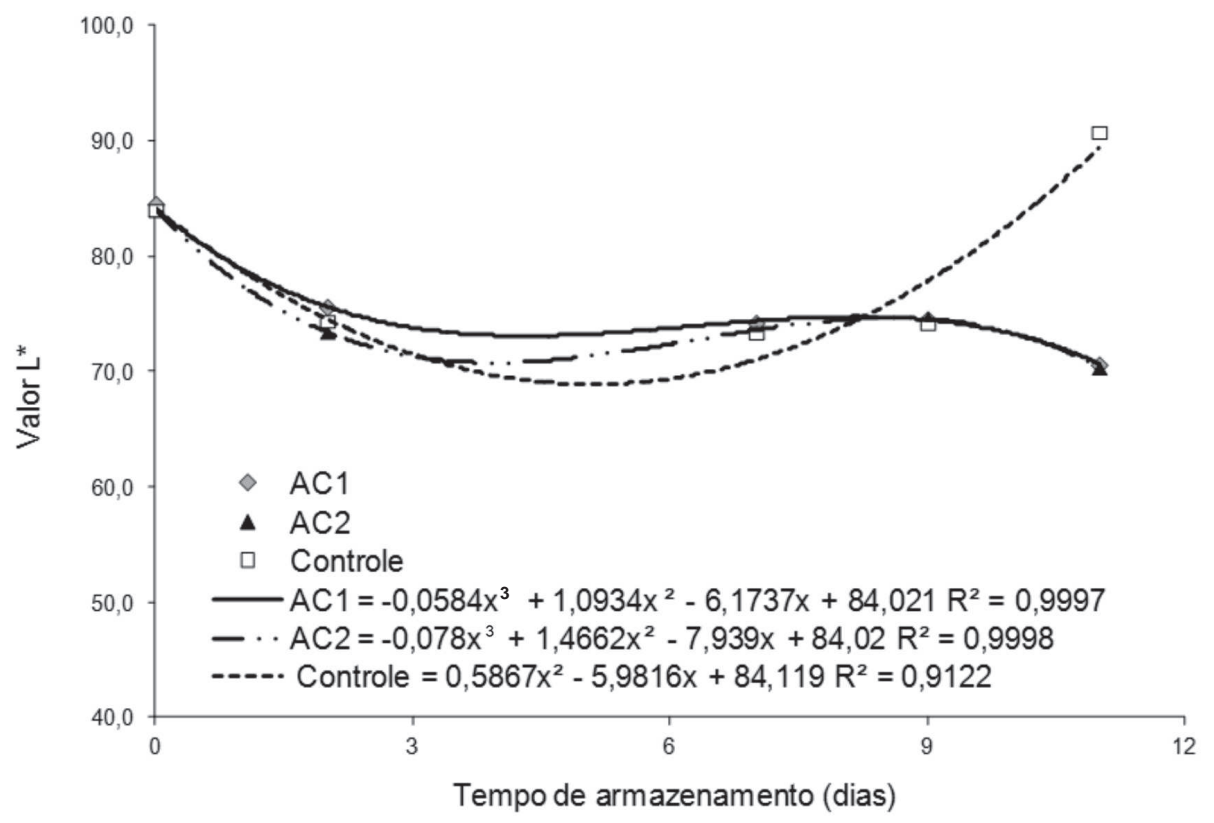

$\mathrm{AC} 1=2 \% \mathrm{O}_{2}$ e $8 \% \mathrm{CO}_{2}, \mathrm{AC} 2=4 \% \mathrm{O}_{2}$ e $8 \% \mathrm{CO}_{2}$ e controle $=$ atmosfera ambiente

$\mathrm{T}=5 \pm 0,5^{\circ} \mathrm{C}, \mathrm{UR}=90 \pm 5 \%$

Figura 5 - Valor L* de milho verde minimamente processado, armazenado sob atmosfera controlada, por 12 dias. 
Tabela 1 - Valores médios de L* e b* de milho verde minimamente processado, armazenado sob atmosfera controlada, por 12 dias

\begin{tabular}{|c|c|c|c|c|}
\hline \multirow{2}{*}{ Parâmetro de cor } & \multirow{2}{*}{$\begin{array}{c}\text { Tempo de } \\
\text { armazenamento (dias) }\end{array}$} & \multicolumn{2}{|c|}{ Atmosfera } & \multirow{2}{*}{ Controle } \\
\hline & & $2 \% \mathrm{O}_{2}$ e $8 \% \mathrm{CO}_{2}$ & $4 \% \mathrm{O}_{2}$ e $8 \% \mathrm{CO}_{2}$ & \\
\hline \multirow[t]{5}{*}{$\mathrm{L}^{*}$} & 0 & $84,00 \mathrm{a}$ & $84,00 \mathrm{a}$ & $84,00 \mathrm{a}$ \\
\hline & 2 & $75,63 \mathrm{a}$ & $73,43 a$ & $74,39 \mathrm{a}$ \\
\hline & 7 & $74,24 \mathrm{a}$ & $73,46 a$ & $73,39 a$ \\
\hline & 9 & $74,56 a$ & $74,62 \mathrm{a}$ & $74,19 \mathrm{a}$ \\
\hline & 11 & $70,63 b$ & $70,33 b$ & $90,76 \mathrm{a}$ \\
\hline \multirow[t]{5}{*}{$\mathrm{b}^{*}$} & 0 & $22,24 a$ & $22,24 a$ & $22,24 a$ \\
\hline & 2 & $33,59 a$ & $32,18 \mathrm{a}$ & $34,05 \mathrm{a}$ \\
\hline & 7 & $31,93 \mathrm{a}$ & $31,95 \mathrm{a}$ & $30,85 \mathrm{a}$ \\
\hline & 9 & $32,06 \mathrm{a}$ & $32,32 \mathrm{a}$ & $32,75 \mathrm{a}$ \\
\hline & 11 & $30,35 \mathrm{a}$ & $30,36 \mathrm{a}$ & $14,80 \mathrm{~b}$ \\
\hline
\end{tabular}

$\mathrm{AC} 1=2 \% \mathrm{O}_{2}$ e $8 \% \mathrm{CO}_{2}, \mathrm{AC} 2=4 \% \mathrm{O}_{2}$ e $8 \% \mathrm{CO}_{2}$ e controle $=$ atmosfera ambiente

$\mathrm{T}=5 \pm 0,5^{\circ} \mathrm{C}, \mathrm{UR}=90 \pm 5 \%$

Como ainda não existe uma legislação sanitária para os produtos minimamente processados, os resultados das análises microbiológicas deste trabalho foram comparados com os Padrões Microbiológicos Sanitários, especificados pela Resolução RDC $n^{\circ} 12$, de 2 de janeiro de 2001, da Agência Nacional de Vigilância Sanitária do Ministério da Saúde, para frutas frescas, in natura, preparadas (descascadas ou selecionadas ou fracionadas), sanificadas, refrigeradas ou congeladas, para consumo direto. A tolerância máxima para este tipo de produto é de $5 \times 10^{2} \mathrm{NMP} \mathrm{g}^{-1}$ (2,7 ciclos log), para coliformes, a 45 ${ }^{\circ} \mathrm{C}$ e, a ausência de Salmonella, em $25 \mathrm{~g}$ do produto (Brasil, 2001). Neste experimento, não foi detectada a presença de coliformes a $45{ }^{\circ} \mathrm{C}$, até nove dias do processamento mínimo. A análise de Salmonella foi realizada somente no sétimo dia de armazenamento, tendo sido confirmada a ausência desse micro-organismo em todas as amostras analisadas. Portanto, os resultados microbiológicos caracterizam o produto como seguro para o consumo humano.

Para melhor avaliação da qualidade microbiológica do milho verde minimamente processado, realizou-se também contagem de coliformes a $35{ }^{\circ} \mathrm{C}$, de bactérias aeróbias psicrotróficas e de fungos filamentosos e leveduras, embora não exista, na legislação, padrão para estes micro-organismos. De forma geral, as contagens da ordem de $10^{5}-10^{6} \mathrm{NMP} \mathrm{g}^{-1}$ ou UFC g-1 $(5-6$ ciclos $\log$ ) são impróprias para o consumo humano, por perda do valor nutricional, alterações sensoriais, riscos de deterioração e, ou, presença de patógenos (Arruda et al., 2004; Berbari et al., 2001). Os valores encontrados neste trabalho ficaram abaixo dos limites preconizados por aqueles autores: menos de $10^{3} \mathrm{NMP} \cdot \mathrm{g}^{-1}$, para coliformes, a $35^{\circ} \mathrm{C}$, menos de $10^{4} \mathrm{UFC} . \mathrm{g}^{-1}$, para fungos filamentosos e leveduras, e menos de $10^{6} \mathrm{UFC} \mathrm{g}^{-1}$, para aeróbios psicotróficos.

\section{CONCLUSÕES}

$\mathrm{O}$ acondicionamento do milho comum minimamente processado sob atmosfera controlada proporcionou perda de massa inferior à obtida em atmosfera ambiente, isto é, na atmosfera ambiente os grão de milho perderam mais água. Por este mesmo motivo, a menor firmeza observada nas espigas armazenadas sob atmosfera controlada promoveu maior maciez para consumo. No entanto, o uso da modificação da atmosfera não influenciou os teores de sólidos solúveis, de açúcares e de carotenoides do milho verde minimamente processado.

Todas as amostras de milho comum minimamente processado analisadas, independentemente do tratamento, apresentaram limites microbiológicos aceitáveis.

Para a comercialização e conservação de milho verde comum minimamente processado 'Embrapa HT1', armazenado sob $5{ }^{\circ} \mathrm{C}$, pode-se recomendar ambas as atmosferas controladas estudadas $\left(2 \% \mathrm{O}_{2}-8 \% \mathrm{CO}_{2}\right.$ e $4 \%$ $\mathrm{O}_{2}-8 \% \mathrm{CO}_{2}$ ); para compor atmosfera modificada ativa, no entanto, para fins operacionais a atmosfera de $4 \%$ $\mathrm{O}_{2}-8 \% \mathrm{CO}_{2}$ é a mais recomendada, por nela ser mais fácil chegar-se à concentração desejada de $\mathrm{O}_{2}$.

Com estes resultados, o estudo para o desenvolvimento de atmosfera modificada ativa passa a ser possível, havendo a necessidade de novos estudos para o avanço da tecnologia.

\section{AGRADECIMENTOS}

Ao Prof. Dr. Adimilson Bosco Chitarra, in memorian, orientador da primeira autora, coautor deste trabalho, amigo e colaborador inestimável da equipe.

Ao CNPq, pela Bolsa de pós-graduação de Mestrado. 


\section{REFERÊNCIAS}

Andrews WH, Flowers RS, Silliker J \& Bailey JS (2001) Salmonella. In: Downes FP \& Ito K (Eds.) Compendium of methods for the microbiological examination of foods. $4^{\text {th }}$ ed. Washington, American Public Health Association. p.357-380.

Arruda MC, Jacomino AP, Spoto MHF, Gallo CR \& Moretti CL (2004) Conservação de melão rendilhado minimamente processado sob atmosfera modificada ativa. Ciência e Tecnologia de Alimentos, 24:53-58.

Azevedo-Meleiro CH \& Rodriguez-Amaya DB (2005a) Carotenoids of endive and New Zealand spinach as affected by maturity, season and minimal processing. Journal of Food Composition and Analysis, $18: 845-855$

Azevedo-Meleiro CH \& Rodriguez-Amaya DB (2005b) Carotenoid composition of kale as influenced by maturity, season and minimal processing. Journal of the Science of Food and Agriculture, 85:591-597.

Barbosa NA, Paes MCD, Teixeira FF, Pereira Filho IA \& Sant' ana RCO (2012) Perda de massa em espigas minimamente processadas de diferentes cultivares de milho doce. In: $29^{\circ}$ Congresso Nacional de Milho e Sorgo: Diversidade e inovações na era dos transgênicos, Águas de Lindóia. Anais, Associação Brasileira de Milho e Sorgo. p.3625-3629.

Barbosa NA (2013) Retenção de carotenoides em milho verde biofortificado com precursores de vitamina A após processamento. Dissertação de Mestrado. Universidade Federal de Lavras, Lavras. 122p.

Berbari SAG, Paschoalino JE \& Silveira NFA (2001) Efeito do cloro na água de lavagem para desinfecção de alface minimamente processada. Ciência e Tecnologia de Alimentos, 21:197-201.

Beuchat LR \& Cousin MA (2001) Yeasts and models. In: Downes FP \& Ito $\mathrm{K}$ (Eds.) Compendium of methods for the microbiological examination of foods. $4^{\text {th }}$ ed. Washington, American Public Health Association. p.209-215.

Brackett RE (1987) Microbiological consequences of minimally processed fruits and vegetables. Journal of Food Quality, 10:195-206

Brasil (2001) Ministério da Saúde. Agência Nacional de Vigilância Sanitária. Resolução nº12. Disponível em: <htpp://www.anvisa.gov.br/ legis/resolucoes/12_01.htm>. Acessado em: 15 de fevereiro de 2007.

Brecht JK, Chau KV, Fonseca SC, Oliveira FAR, Silva FM, Nunes MCN \& Bender RJ (2003) Maintaining optimal atmosphere conditions for fruits and vegetables throughout the postharvest handling chain. Postharvest Biology and Technology, 27:87-101.

Camacho C, Alfonzo B, Bertorelli LO \& Venanzi F (2001) Estudio de la estabilidad de las características químicas, microbiológicas y sensoriales de mazorcas refrigeradas de híbridos de maíz super dulce. Archivos Latinoamaricanos de Nutrición, 51:180-186.

Cantwell MI (2002) Summary table of optimum handling conditions for fresh produce. In: Kader AA (Ed.) Postharvest Technology of Horticultural Crops. $3^{\mathrm{a}}$ ed. Oakland, University of Califonia. p.511-518

Chitarra MIF (2000) Tecnologia e qualidade pós-colheita de frutos e hortaliça. Lavras, UFLA. 68p.

Chitarra MIF \& Chitarra AB (2005) Pós-colheita de frutos e hortaliças: fisiologia e manuseio. $2^{\mathrm{a}}$ ed. Lavras, UFLA. 249p.

Cousin MA, Jay JM \& Vasavada PC (2001) Psychrotrophic Microorganisms. In: Downes FP \& Ito K (Eds.) Compendium methods for the microbiological examination of foods. $4^{\text {th }}$ ed. Washington, American Public Health Association. p.159-166.
Creech RG (1968) Carbohydrate synthesis in maize. Advances in Agronomy, 20:275-289.

Deák T, Heaton EK, Hung YC \& Beuchat LR (1987) Extending the shelf life of fresh sweet corn by shrink-wrapping, refrigeration, and irradiation. Journal of Food Science, 52:1625-1631.

Ferreira DF (2000) Análises estatísticas por meio do SISVAR para windows versão 4.0. In: 45a Reunião Anual da Região Brasileira da Sociedade Internacional de Biometria, São Carlos. Resumos, UFSCar. p.235.

International Organization for Standardization (2003) ISO 2173: Fruit and vegetable products: determination of soluble solids content: refractometric method. $2^{\text {nd }}$ ed. Genève, International Organization for Standardization. $8 \mathrm{p}$.

International Organization for Standardization (1998) ISO 750: Fruit and vegetable products: determination of titratable acidity. $2^{\text {nd }} e d$. Genève, International Organization for Standardization. 4p.

Kader AA (2002) Modified atmospheres during transport and storage. In: Kader AA (Ed.) Postharvest technology of horticultural crops. $3^{\text {a }}$ ed. Oakland, University of Califonia. p.135-148.

Lana MM \& Finger FL (2000) Atmosfera modificada e controlada. Brasília, Embrapa Comunicação para Transferência de Tecnologia. 34p.

Marcos SK, Honório SL, Jorge JT \& Avelar JAA (1999) Influência do resfriamento do ambiente de armazenamento e da embalagem sobre o comportamento pós-colheita do milho verde. Revista Brasileira de Engenharia Agrícola e Ambiental, 3:41-44.

Macrae R (1998) Food science and technology: a series of monoghraphys: HPLC in food analysis. $2^{\text {nd }}$ ed. New York, Academic. 77 p.

Mamede AMGN, Fonseca MJO, Soares AG, Chitarra AB, Ferreira JCS, Modesta RCD \& Jannuzzi G (2006) Determinação da firmeza de grãos de milho verde minimamente processado. In: IV Encontro Nacional Sobre Processamento Mínimo de Frutas e Hortaliças e I Simpósio Ibero-Americano de Vegetais Frescos Cortados, São Pedro. Resumos, ESALQ-USP. 192p.

Mamede AMGN, Chitarra AB, Fonseca MJO, Soares AG, Ferreira JCS \& Lima LCO (2009) Conservação pós-colheita de espigas de milho verde minimamente processado sob diferentes temperaturas. Ciência e Agrotecnologia, 33:200-206.

Morton RD (2001) Aerobic Plate Count. In: Downes FP \& Ito K (Eds.) Compendium methods for the microbiological examination of foods. $4^{\text {th }}$ ed. Washington, American Public Health Association. p.63-67.

Niizu PY (2003) Fontes de carotenoides importantes para a saúde humana. Dissertação de Mestrado. Universidade Estadual de Campinas, Campinas.76p

Nunes MCN \& Emond JP (2003) Storage temperature. In: Bartz JA \& Brecht JK (Eds.) Postharvest physiology and pathology of vegetables. New York, M Dekker. p.209-228.

Paes MCD, Modesta RCD \& Gama EEG (2004) Textura em grãos de híbridos experimentais destinados à produção de milho verde. In: $25^{\circ}$ Congresso Nacional de Milho e Sorgo, Cuiabá. Anais, Embrapa Milho e Sorgo. 513p.

Pereira Filho IA \& Cruz JC (2003) Colheita, transporte e comercialização. In: Pereira Filho IA (Ed.) O cultivo do milho verde. Brasília, Embrapa Informação Tecnológica. p.183-194.

Rodriguez-Amaya DB (2001) A guide to carotenoid analysis in food Washington, ILSI. 64p.

Rodriguez-Amaya DB \& Kimura M (2004) Harvest Plus Handbook for Carotenoid Analysis. Washington, International Food Policy Research Institute. 58p. 
Scott CE \& Eldridge AL (2005) Comparison of carotenoid content in fresh, frozen and canned corn. Journal of Food Composition and Analysis, 18:551-559.

Soliva-Fortuny RC \& Martín-Belloso O (2003) New advances in extending the shelf-life of fresh-cut fruits: a review. Trends in Food Science \& Tecnology, 14:341-353.

Swanson MJ, Petran RL \& Hanli JH (2001) Cul-ture methods for enumeration of microorganisms. In: Downes FP \& Ito K (Eds.) Compedium of Methods for the Microbiological Examination of foods. $4^{\text {th }}$ ed. Washington, American Public Health Association. p.53-62.
Tsai CY, Salamini F \& Nelson OE (1970) Enzymes of carbohydrate metabolism in developing endosperm of maize. Plant Physiology, 46:299-336.

Vilas Boas EVB (2002) Qualidade de alimentos vegetais. Lavras, UFLA. $68 \mathrm{p}$.

Zagory D \& Kader AA (1988) Modified atmosphere packing of fresh produce. Food Technology, 42:70-77.

Zhu S, Mount JR \& Collins JL (1992) Sugar and Soluble Solids Changes in Refrigerated Sweet Corn (Zea mays L). Journal of Food Science, 57:454-457. 